\title{
Evaluating the role of clinical officers in providing reproductive health services in Kenya
}

\author{
Marianne Corine Darwinkel ${ }^{1 *}$ (D), Julius Maina Nduru', Reuben Waswa Nabie ${ }^{1}$ and John Anzetse Aswani ${ }^{2}$
}

\begin{abstract}
Background: Most sub-Saharan African countries have too few reproductive health (RH) specialists, resulting in high RH-related mortality and morbidity. In Kenya, task sharing in RH began in 2002, with the training of clinical officer(s)-reproductive health (CORH). Little is known about them and the extent of their role in the health system.

Methods: In 2016, we conducted a retrospective, quantitative two-stage study in Kenya to evaluate the use of $\mathrm{CORH}$ and 28 of their curriculum-derived $\mathrm{RH}$ competencies, to determine their contribution to expanded access to $\mathrm{RH}$ care. CORH were surveyed, using structured questionnaires and telephone interviews. Data on the frequency with which CORH used specified competencies were collected from health records in selected facilities.

Results: Forty-nine of all 104 CORH participated in the survey (47\%). Forty-eight (98\%) had worked in the clinical area, and 79\% were still engaging in clinical work. All 48 worked in emergency obstetrics, emergency gynaecology, and nonemergency $\mathrm{RH}$, and 38 (79\%) filled clinical leadership positions. Vasectomy was least performed, by only 9 (18\%) CORH. All other competencies were applied by at least half of the CORH, and 22 competencies by more than three quarters. Forty-one (84\%) CORH performed caesarean section (CS). Teaching and management were other common responsibilities.

Data were collected from 12 facilities and analysed for 11. They generally confirmed the initial survey findings: $\mathrm{CORH}$ worked as obstetrics and gynaecology consultants and used most of their competencies. Analysis was based on 118 months of theatre records. CORH made significant contributions to their facility's capacity to perform RH surgery: most respondents performed at least $25 \%$ of these surgeries. They performed an average of six CS per month and more than $25 \%$ of perineal tear repairs (33\%), uterus repairs (33\%), manual placenta removals (26\%), bilateral tubal ligations (39\%), and cervical cancer staging (27\%). Some experienced CORH conducted procedures beyond their training.
\end{abstract}

Conclusions: $\mathrm{CORH}$ expand access to emergency RH care. Their contributions span all areas of obstetric and gynaecological care, mentoring new health workers and expanding their scope of practice. However, the generally poor status of records documenting healthcare provision limits their usability in evaluation and research.

Keywords: Reproductive health, Kenya, Obstetric surgical procedures, Caesarean section, Health manpower, Physician assistant, Specialisation

\footnotetext{
* Correspondence: marianne.darwinkel@chpkenya.org

${ }^{1}$ Community Health Promotion Kenya, P.O. Box 1045, Mtwapa 80109, Kenya

Full list of author information is available at the end of the article
}

C The Author(s). 2018 Open Access This article is distributed under the terms of the Creative Commons Attribution 4.0 International License (http://creativecommons.org/licenses/by/4.0/), which permits unrestricted use, distribution, and reproduction in any medium, provided you give appropriate credit to the original author(s) and the source, provide a link to the Creative Commons license, and indicate if changes were made. The Creative Commons Public Domain Dedication waiver (http://creativecommons.org/publicdomain/zero/1.0/) applies to the data made available in this article, unless otherwise stated. 


\section{Background}

Worldwide, 800 women die every day from preventable causes related to pregnancy and childbirth. Almost all of them (99\%) live in a developing country [1]. Few countries in sub-Saharan Africa have adequate resources or sufficient skilled health workers to provide critical, evidence-based interventions that improve reproductive health $(\mathrm{RH})$ and reduce maternal mortality [2]. Task sharing (or task shifting) is a strategy that countries around the world employ to address gaps in access and availability caused by a shortage of physicians. This strategy creates cadres of associate clinicians ${ }^{1}$ who perform what would traditionally be part of a physician's job. In 2008, associate clinicians, previously known as non-physician clinicians, were used in 25 out of 47 countries in sub-Saharan Africa [3].

The absence of physicians, especially in rural areas, is problematic when clients need comprehensive emergency obstetric care (CEmOC), specifically caesarean section (CS). Kenya has a very low physician-to-population ratio-approximately five doctors for every 100000 people $[4,5]$ - and most of them work in cities and larger towns. Research indicates that associate clinicians, or clinical officers, are present in most health facilities, are less expensive to train and faster to deploy than physicians and achieve similar outcomes. Additionally, there is better retention of clinical officers in rural areas [6-10]. Based on these findings, the World Health Organization (WHO) recommends that clinical officers who have received additional training be allowed to perform CS with ongoing monitoring [2]. In addition to CEmOC, other $\mathrm{RH}$ challenges that can be managed by trained clinical officers include management of rape cases, infertility, and early diagnosis and treatment of cervical cancer.

Task sharing with clinical officers has occurred in Kenya for decades; however, information about clinical officers is scarce. For example, the total number of clinical officers in Kenya, their role in the health system, or the extent to which they provide care in rural facilities are not well documented [11-13]. Recent studies suggest that a general lack of understanding of their skills and training causes them to be underused, particularly in health promotion and prevention services $[12,13]$. To become a clinical officer, one completes a 3-year post-secondary school training program followed by 1 year internship in a hospital. Completion of this program plus 2 years' work experience qualifies clinical officers to specialise in one of eight clinical fields: anaesthesia; ophthalmology; ear, nose, and throat; paediatrics; lung and skin; orthopaedics; or oncology. In 2002, the RH specialisation was added to increase the availability of $\mathrm{RH}$ services in Kenya, and clinical officer(s)-reproductive health $(\mathrm{CORH})$ have been trained in a one-and-half-year training program followed by a 6-month internship every year since then. The training curriculum was designed to produce skilled associate clinicians who can comprehensively meet the RH needs of individuals, families, and the community, beyond those met by other clinical officers and nurse-midwives. The $\mathrm{CORH}$ competencies are managing $\mathrm{RH}$ conditions and providing $\mathrm{CEmOC}$, long-term family planning, and medical legal services. Training takes 24 months, six of which are spent gaining practical skills in an internship.

Currently, about 100 CORH work in Kenya's health system. Despite their formal deployment, CORH do not feature in government policies, regulations, and strategic plans, and literature about them is scant. Kenya has a maternal mortality ratio of 360 deaths per 100000 births [14]. Considering the ambitious goal of the Kenyan Health Sector Strategic and Investment Plan to reduce maternal and neonatal deaths by half, [15] more information about $\mathrm{CORH}$, the frequency with which they carry out medical procedures, and their role and clinical competencies are essential. Anecdotal information and the few studies indicate that CORH are significantly underused $[16,17]$.

Our quantitative study evaluated the use of clinical competencies of $\mathrm{CORH}$ specified in their curriculum, training manuals, and internship logbooks to assess their contribution to expanded access to CEmOC. The study objectives were to determine the percentage of $\mathrm{CORH}$ carrying out emergency and invasive procedures; the frequency with which they carry out specific CEmOC procedures and manage specific gynaecological emergencies; the proportion of surgical procedures performed by CORH relative to other service providers; the diagnostic, family planning, and other non-emergency therapeutic procedures CORH perform; and other specific conditions that they manage in the absence of other skilled healthcare providers.

\section{Methods \\ Study design}

This retrospective, quantitative study was carried out in various parts of Kenya in two stages between April and September 2016: a survey among CORH followed by collection of data from health records in various facilities.

The initial survey comprised structured telephone interviews using a questionnaire (Additional file 1). After piloting the questionnaire among general clinical officers and medical officers, 47 interviews with $\mathrm{CORH}$ were held between April and September 2016. Interviews focused on the field of the CORH's work (clinical, teaching, research, or management); the extent to which they used $28 \mathrm{RH}$ competencies in which they were trained (10 in emergency obstetrics, 3 in emergency gynaecology care, and 15 in nonemergency $\mathrm{RH}$ care); and in which facilities. These competencies were derived from the CORH curriculum and excluded competencies shared with other cadres with less training, such as normal delivery and provision of non-permanent family planning methods. 
During the second stage, data was collected from medical records, using structured data forms. Records came from 12 facilities in 8 out of Kenya's 47 counties where a $\mathrm{CORH}$ worked or had been working. The data-collection form was piloted in a facility not sampled for the study. Inclusion criteria were the following: public facility, in-patient capacity, over 50 deliveries per month, and reported application of most $\mathrm{RH}$ competencies by the interviewed CORH. The last criterion aimed at sampling facilities with conducive environments for CORH to carry out their scope of practice, because an earlier study indicated barriers in many facilities [16]. The hospital data analysis therefore indicates the potential contribution of CORH to RH care for Kenyans; it does not represent all facilities where CORH worked.

Data on the frequency with which $\mathrm{CORH}$ and other facility staff applied the 28 competencies were collected from the facility in-charges and the facility CORH, general records, labour ward records, theatre books, and, where available, manual vacuum aspiration (MVA) records. We counted the number of procedures performed or assisted by a CORH and the total number of each procedure performed within each facility. Information was collected for 2015, if the CORH was in the facility that year; if not, the nearest year was selected. We found significant problems with record keeping in facilities, making it impossible to collect all desired data from the intended years, resulting in data from nine theatre records, eight labour ward records, and five MVA records.

\section{Data collectors}

Thirteen people were involved in data collection: three investigators and ten research assistants. A 1-day training was conducted for all team members on the tools and telephone interview techniques.

\section{Recruitment of participants and selection of facilities}

Participants were recruited systematically. First, they were identified from a list of all CORH graduates obtained from the training institution. Contact information was then obtained for about half of them from the Clinical Officers' Council. Using these initial contacts, subsequent contacts were traced through a CORH WhatsApp group. We interviewed all $\mathrm{CORH}$ whom we managed to contact and who agreed to be interviewed. Facilities were purposefully selected to include various regions of Kenya and various levels of health facilities.

\section{Approvals for the study}

The study obtained ethical approval from Kenyatta National Hospital and the University of Nairobi Ethics \& Research Committee (P645/10/2015), and the National Commission on Science, Technology and Information (NACOSTI) approved the research activities (NACOSTI/
$\mathrm{P} / 16 / 72466 / 10271)$. Permission to access records in health facilities was obtained from the Ministry of Health. Kenya's current devolved county governance system required another layer of approvals from the research department in each county where data were collected.

\section{Study analysis}

All quantitative data were entered directly in Epidata and later exported to Excel for analysis of frequencies.

\section{Results \\ Survey results \\ General respondent information}

Data from the Kenya Medical Training College, where the $\mathrm{CORH}$ training is conducted, indicated that 104 CORH, 61 (59\%) males and 43 (41\%) females, had graduated by $2015 .^{2}$ We were able to contact 73 of them for the survey and interviewed 49 (47\%). Six CORH declined to be interviewed; 18 agreed to be interviewed but were subsequently unavailable. Twenty-nine CORH could not be reached using their telephone numbers, and two had died.

The $49 \mathrm{CORH}$ interviewed were representatives from all trainings since 2002, except the 2011 training, which had only four students. The distribution of our sample reflects the distribution of the total population of $\mathrm{CORH}$ over the various classes.

\section{Career paths}

Out of the $49 \mathrm{CORH}$ surveyed, 35 (71\%) worked primarily in the clinical area, with teaching and management as other common responsibilities. Fifteen CORH (31\%) had multiple workplaces, and four (8\%) reported carrying out specific clinical CORH competencies at a secondary place of work. Only one CORH never worked in the clinical area, but had always been involved in RH management, teaching, research, and fundraising. All other $48 \mathrm{CORH}$ had managed cases in all the three RH fields: emergency obstetrics, emergency gynaecology, and nonemergency RH. All but $10(21 \%)$ of these $48 \mathrm{CORH}$ had filled clinical leadership positions in $\mathrm{RH}$, by being responsible for one or more of the maternity wards (antenatal, labour, and postnatal), the high-risk antenatal clinics, or the gynaecological and/or gender-based violence clinic. Thirteen CORH (26\%) reported responsibilities in all six areas.

\section{Application of specific competencies}

The survey data showed that, out of the 28 competencies, only vasectomy was rarely performed (Table 1). The reason given was generally "lack of clients." Out of the 41 who performed CS, $6 \mathrm{CORH}$ commented that they were allowed only to assist with CS or to do it under supervision. 
Table 1 Reported application of specific competencies by 49 clinical officers-reproductive health

\begin{tabular}{|c|c|c|}
\hline Competency & Frequency & Percentage (\%) \\
\hline \multicolumn{3}{|l|}{ Emergency Obstetric Care (10 competencies) } \\
\hline Manage pre-eclampsia* & 47 & 95.9 \\
\hline Manage postpartum haemorrhage & 47 & 95.9 \\
\hline Manage puerperal sepsis & 47 & 95.9 \\
\hline Manual removal of retained placenta & 46 & 93.9 \\
\hline Induce and augment labour & 45 & 91.8 \\
\hline Repair cervical tear & 42 & 85.7 \\
\hline Perform caesarean section & 41 & 83.7 \\
\hline Repair perineum 3rd and 4th degree tear & 38 & 77.6 \\
\hline $\begin{array}{l}\text { Secondary repair of burst abdomen after } \\
\text { caesarean section }\end{array}$ & 34 & 69.4 \\
\hline Vacuum extraction of baby & 28 & 57.1 \\
\hline \multicolumn{3}{|l|}{ Gynaecological emergency care (3 competencies) } \\
\hline Perform manual vacuum aspiration & 48 & 98.0 \\
\hline Manage gender-based violence & 42 & 85.7 \\
\hline Manage ectopic pregnancy, including laparotomy & 37 & 75.5 \\
\hline \multicolumn{3}{|l|}{ Nonemergency reproductive health (15 competencies) } \\
\hline Infertility ${ }^{a}$ & 47 & 95.9 \\
\hline $\begin{array}{l}\text { Visual inspection with acetic acid and visual inspection } \\
\text { with Lugol's iodine }\end{array}$ & 46 & 93.9 \\
\hline Adolescent reproductive health-related issues ${ }^{\mathrm{b}}$ & 46 & 93.9 \\
\hline Gynaecological disorders in puberty & 44 & 89.8 \\
\hline Sexual dysfunction & 44 & 89.8 \\
\hline Removal of lost intrauterine contraceptive device & 43 & 87.8 \\
\hline Dilatation and curettage & 40 & 81.6 \\
\hline Bilateral tubal ligation ${ }^{c}$ & 40 & 81.6 \\
\hline Insertion and removal of MacDonald stitch & 39 & 79.6 \\
\hline Papanicolaou test & 38 & 77.6 \\
\hline Gestational trophoblastic disease & 37 & 75.5 \\
\hline Staging of cervical cancer & 36 & 73.5 \\
\hline Cervical biopsy & 35 & 71.4 \\
\hline Endometrial biopsy & 25 & 51.0 \\
\hline Vasectomy ${ }^{* *}$ & 9 & 18.3 \\
\hline
\end{tabular}

*1 missing value

**9 missing values

${ }^{a}$ For patients dealing with infertility, $\mathrm{CORH}$ are trained in evaluation and counselling of couples, identification and interpretation of laboratory and imaging investigations, and, to some extent, management of infertility, e.g. hydrotubation and myomectomy.

${ }^{b}$ In light of Kenya's high teen pregnancy rate, many government guidelines require RH services that are accessible and acceptable to the youth. Competencies of the $\mathrm{CORH}$ that related to youth sexual and $\mathrm{RH}$ care are diagnosis and management of various menstrual problems and recognition of congenital conditions, including hereditary conditions and problems such as imperforate hymen.

c Only bilateral tubal ligation and vasectomy were included as CORH skills, because the other family planning competencies, such as intrauterine contraceptive device insertion and provision of injectable contraceptives and implants, are also done by other staff (e.g. general clinical officers and midwives).

Resistance from other practitioners and shortcomings in physical infrastructure and equipment were given as reasons for not performing CS. The three gynaecological emergency care competencies were applied by more than three quarters of the CORH. Three of the CORH $(6 \%)$ had applied all 15 nonemergency RH competencies, and 11 of these competencies were applied by more than $75 \%$ of the
CORH. Table 1 contains details on the specified competencies and the percentage of CORH applying them.

The survey uncovered additional competencies that the respondents considered part of their practice: management of patients with HIV/AIDS (mentioned thrice), cryotherapy, balloon tamponade, ${ }^{3}$ subtotal hysterectomy, pelvic abscess removal, court attendance in rape cases, leading ward 
rounds, medical camps, and outreach services (all mentioned once).

\section{Findings from hospital record data}

Data from one of the 12 facilities were not included in the analysis, because few records were available. The 11 remaining facilities varied considerably in $\mathrm{RH}$ workload (average deliveries varied from 56 to 687 per month). Two facilities had no operating theatre, and five lacked a gynaecologist.

The survey findings generally were corroborated by the hospital data. General records and information from the facility in-charges and facility CORH confirmed that CORH were mostly used as consultants, in all areas of obstetrics and gynaecology. Survey findings and hospital data both indicated that the participation of CORH in RH surgery varied. In facilities where the $\mathrm{CORH}$ had worked many years, he or she appeared regularly in records for elective operations and uncommon emergency procedures and less than expected for common procedures, such as CS. They functioned as de facto consultants and supervisors of medical officers and medical officer interns for common procedures such as CS and MVA. In other facilities, $\mathrm{CORH}$, medical officers, and medical officer interns shared common RH surgery. In a few facilities, tension appeared to exist between medical officers and CORH in allocating the CORH surgical responsibilities. In one facility, this appears to have resulted in a sharp decline in participation by the CORH in theatre accompanied by an observable increase in delivery-related referrals.

Some procedures, although outlined in the curriculum, were never performed by CORH. For example, during the period studied, no vacuum extraction was mentioned in the labour ward records and no vasectomy was recorded in the theatre records. For two procedures, findings from the hospital data were different from the survey results. Examination under anaesthesia for cervical cancer staging was commonly recorded as being performed by $\mathrm{CORH}$, but fewer than $75 \%$ of the $\mathrm{CORH}$ reported doing so. In contrast, survey data showed that 94\% of the CORH engaged in manual removal of the placenta, but this procedure was rarely mentioned in the hospital records.

In none of the 10 facilities with a theatre was the CORH consistently the only RH surgeon. Four of the facilities had relatively numerous staff who performed RH surgery; in six facilities, the CORH worked on a team of two to five RH surgeons. In two of the facilities, the $\mathrm{CORH}$ supervised medical officer interns and newly posted medical officers. Overall, CORH contributed much to RH surgery, with most $\mathrm{CORH}$ performing at least $25 \%$ of them in their facilities.

From the nine theatre records, we analysed data for a total of 118 months (Table 2). The number of CS that the
Table 2 Caesarean sections per month by clinical officersreproductive health in nine facilities over 118 months

\begin{tabular}{lll}
\hline No of CS per month & Number of months & Percent (\%) \\
\hline No CS & 15 & 16.0 \\
1-4 CS (max. 1/week) & 38 & 40.4 \\
5-8 CS (max. 2/week) & 20 & 21.3 \\
More than 9 CS & 21 & 22.3 \\
& $94^{*}$ & 100 \\
\hline
\end{tabular}

*13 months with missing data on CS by CORH and 11 months where CORH refused to go to theatre

CORH performed each month varied from zero to 31, with a mean of six per month. Most months that the CORH did not perform CS were because they were on leave or out for training. Having a CORH on staff improved CS availability; CORH performed more than half of the CS in almost $40 \%$ of the months. Theatre records showed that CORH performed more than $25 \%$ of three other obstetric emergency procedures in those facilities (Table 3).

We collected data on 641 complicated deliveries from 8 labour ward records. However, analysis of the contribution of the $\mathrm{CORH}$ in managing complications during delivery was only possible in one facility. In all other facilities, it was hampered by inconsistencies in, and incompleteness of, the data, including torn and tattered records, many blanks, and failure to record consultations during delivery.

The hospital records showed, on average, between one and two laparotomies for suspected ectopic pregnancy every month. Some theatre records did not record any, whereas the largest facility had 2 months with nine laparotomies for ectopic pregnancy. In the 118 months, 183 laparotomies for ectopic pregnancies were performed, 28 (15\%) of these by a CORH.

Only five facilities kept MVA records; even those were scanty. Only one facility kept records in accordance with government guidelines. The five facilities reported between 4 and 47 (a mean of 15) MVAs per month. Only three facilities recorded details about the MVA (indication, who performed the procedure, complications, or referral). The CORH performed $24 \%$ of the MVAs in those facilities.

Ten of the 11 hospitals did not have a gender-based violence clinic, but called upon the CORH or a medical officer when a rape case or sexual assault case was reported. It was not possible to get quantitative data that specified the involvement of the CORH.

In the facilities, theatre records were used to assess the frequency with which $\mathrm{CORH}$ performed various procedures (Table 4). It was not possible to get substantive quantitative information on nonsurgical consultations by the CORH from the hospital records. In addition to the curriculum-derived competencies, two procedures were clearly within the scope of $\mathrm{CORH}$ and frequently performed: marsupialization of Bartholin cyst and avulsion 
Table 3 Other emergency obstetric procedures done during 118 months in nine facilities

\begin{tabular}{llll}
\hline Procedure & Total & \multicolumn{2}{l}{ By CORH } \\
\cline { 3 - 4 } & & Number & Percentage (\%) \\
\hline Repair perineal tear* & 12 & 4 & 33.3 \\
Repair ruptured uterus & 9 & 3 & 33.3 \\
Manual removal of the placenta & 31 & 8 & 25.8 \\
Repair cervical tear & 40 & 8 & 20.0 \\
Re-laparotomy after CS ("burst & 30 & 3 & 10.0
\end{tabular}

abdomen")

*Note: Perineal repairs in theatre only reported in two facilities; in the others, no perineal tear repair was reported. This is unlikely and might suggest either grade III/IV perineal tears were often overlooked, or repairs were done in labour ward

of cervical polyps. No vasectomy was documented. Hydatiform mole, as an indication for MVA, was mentioned once.

In line with the survey results, the theatre books displayed records of several procedures performed by $\mathrm{CORH}$ beyond the scope of their training curriculum (Table 5). These advanced procedures were mainly carried out by experienced CORH.

\section{Discussion}

This study initially aimed at assessing the impact of $\mathrm{CORH}$ in improving access to CEmOC in Kenya since the inception of the course in 2002. However, in almost all hospitals, records were incomplete and they sometimes contained conflicting data, making inaccuracies in source records a major limitation of this study. Due to these widespread deficiencies, the scope of the study was scaled down to focus on establishing the contribution of $\mathrm{CORH}$ in expanding access to $\mathrm{CEmOC}$, gynaecological emergency care, and nonemergency $\mathrm{RH}$ care. Where possible, findings were triangulated, e.g. through comparing labour ward records and theatre records or through extracting data from patient files.

All CORH surveyed were still working in Kenya in $\mathrm{RH}$, more than 7 years (on average) after their training. Most $\mathrm{CORH}$ provided clinical $\mathrm{RH}$ care and many held leadership positions in the clinical field. They applied most of the 28 specialist competencies in their curriculum, with only vasectomy being rarely performed. In addition, $83 \%$ of the CORH reported performing major $\mathrm{RH}$ surgery, such as CS, a relevant finding as it suggests that more $\mathrm{CORH}$ are overcoming earlier reported barriers to carrying out invasive procedures [16]. This retention and integration of associate clinicians in the country and in their field of expertise, in addition to being cheaper to train and deploy, is in line with findings of other studies [7-9] and significant, considering the brain drain to developed countries that Kenya experiences.

Analysis of theatre records clearly demonstrates the significant role the CORH play in saving mothers with complications during delivery by being able to task share in some critical CEmOC procedures, specifically CS and managing post-partum haemorrhage [18]. The contribution of CORH in emergency gynaecological care was less pronounced, relatively smaller, and difficult to assess. Laparotomy for ectopic pregnancy was not performed frequently by CORH. In most facilities, MVA records were poorly if at all kept, making it impossible to ascertain the actual contribution of $\mathrm{CORH}$ in performing this simple but lifesaving procedure. From the limited available records, CORH did relatively few MVAs. When these findings were discussed with the participating $\mathrm{CORH}$, some said they mainly engaged in MVAs when supervising juniors (general clinical officers) or when complications arose. It was not possible to determine the role of $\mathrm{CORH}$ in non-surgical consultations like for sexual violence or other cases in the obstetric and gynaecological clinic, as the hospital records did not record specific patients or specific cases against specific clinicians.

Some discrepancies were observed between the survey data and the hospital records. A procedure like manual placenta removal was cited as commonly performed by $\mathrm{CORH}$ in the survey, but labour ward and theatre records captured very few. In contrast, theatre records showed more frequent staging of cervical cancer by CORH than did the survey results. This finding warrants more investigations as cervical cancer is a significant public health problem in Kenya [19].

Table 4 Theatre procedures in nonemergency reproductive health care over the 118 months in nine facilities

\begin{tabular}{|c|c|c|c|c|c|c|c|}
\hline \multirow[t]{2}{*}{ Procedure } & \multicolumn{3}{|c|}{ Overall per month } & \multicolumn{3}{|c|}{ By CORH per month } & \multirow{2}{*}{$\begin{array}{l}\text { Percentage by } \\
\text { CORH (\%) }\end{array}$} \\
\hline & Min & Max & Mean & Min & Max & Mean & \\
\hline Avulsion of cervical polyp & 0 & 4 & 0.10 & 0 & 1 & 0.04 & 40.0 \\
\hline Bilateral tubal ligation & 0 & 13 & 1.92 & 0 & 8 & 0.75 & 39.1 \\
\hline Staging of cervical cancer-examination under anaesthesia & 0 & 10 & 1.34 & 0 & 5 & 0.36 & 26.9. \\
\hline Dilatation and curettage & 0 & 11 & 1.44 & 0 & 4 & 0.35 & 24.3 \\
\hline Inserting MacDonald stitch & 0 & 9 & 1.06 & 0 & 5 & 0.25 & 23.6 \\
\hline Marsupialization of Bartholin cyst & 0 & 6 & 0.69 & 0 & 3 & 0.16 & 23.2 \\
\hline Removal of lost intrauterine contraceptive device & 0 & 3 & 0.13 & 0 & 1 & 0.01 & 7.7 \\
\hline
\end{tabular}


Table 5 Advanced procedures by clinical officers-reproductive health over the 118 months in nine facilities

\begin{tabular}{|c|c|c|}
\hline Procedure & $\begin{array}{l}\text { Number of facilities } \\
\text { where the procedures } \\
\text { were performed by CORH }\end{array}$ & $\begin{array}{l}\text { Number of } \\
\text { procedures performed }\end{array}$ \\
\hline $\begin{array}{l}\text { Hysterectomy (both } \\
\text { subtotal and total) }\end{array}$ & 6 & 17 \\
\hline Myomectomy & 3 & 4 \\
\hline Ovarian cystectomy & 2 & 3 \\
\hline $\begin{array}{l}\text { Incision } \\
\text { haematocolpos }\end{array}$ & 2 & 2 \\
\hline Vulvectomy & 1 & 1 \\
\hline Fistulectomy & 1 & 1 \\
\hline $\begin{array}{l}\text { Intra-abdominal } \\
\text { abscess }\end{array}$ & 1 & 1 \\
\hline Prostatectomy & 1 & 5 \\
\hline Herniorrhaphy & 1 & 1 \\
\hline
\end{tabular}

Another finding was that some experienced $\mathrm{CORH}$ did more procedures than those in the curriculum. For example, both the survey and records indicated that $\mathrm{CORH}$ perform advanced surgical procedures such as subtotal hysterectomy, ovarian cystectomy, and draining of pelvic abscesses. This observation could be viewed from two perspectives: CORH could be seen as overstepping the mandate outlined in their curriculum, or they could be seen as a resource to be built on, through official training and task sharing, to make surgical RH care more accessible to communities in remote areas.

In our earlier study [16], the discrepancy in financial compensation between the CORH and other surgical RH staff was problematic. The Kenyan salary and remuneration guidelines state that, for the same work, medical officers get on-call allowance, but CORH do not. Although $\mathrm{CORH}$ continued to perform within and even beyond their scope of practice, the discrepancy in remuneration could hinder expansion of CORH services. There were clear indications of this, as two CORH working in the included facilities felt they were misused by the system and had refused to continue working in theatre.

A substantial proportion of the CORH was involved, part-time or fulltime, in training in general clinical officer students. Others mentored other less-experienced health workers-including medical interns and medical officers. Medical officers spend only 3 months in RH during their 1 year internship. Once qualified, they generally work for only one or a few years before moving on to specialise. In comparison, CORH have a more extensive clinical exposure during training (6 months as interns, in addition to 3 months during their basic training) and a more sustained presence at their workstations, making them reliable resource persons in $\mathrm{RH}$ for other medical workers. This is significant given that the objective of the initiators of the
CORH training was not only to improve access to quality $\mathrm{RH}$ care, but also to improve the level of $\mathrm{RH}$ training of general clinical officers, by creating role models and trainers in the profession [16].

One additional observation that was not the object of our study, but was quite prominent, was the wide variation in the frequency of diagnosis of certain RH problems, for example post-partum blood loss, and performance of specific $\mathrm{RH}$ procedures, for example examination under anaesthesia for cervical cancer or laparotomy for ectopic pregnancy. In several cases, the frequency of diagnosis and procedures varied so widely that it appeared unlikely to reflect variation in prevalence. Possible other causes of this variation could be problems with recognising certain conditions, lack of appropriate referral, or lack of proficiency among advanced RH staff (surgical staff, including CORH) to perform certain procedures.

\section{Conclusions}

Training of CORH is effective in directly increasing human resources for specialist $\mathrm{RH}$ healthcare. $\mathrm{CORH}$ in clinical practice have roles and responsibilities in all areas of obstetric and gynaecological care, with an emphasis on acute care, specifically $\mathrm{CEMOC}$, and their absolute and relative contributions are substantive. They are retained well within Kenya and within their field of specialisation.

$\mathrm{CORH}$ also contribute to $\mathrm{RH}$ specialist care through support they give to others in the field, specifically by training and mentoring new health workers, including medical officers and medical officer interns.

Our study is, to our knowledge, the first that has quantified the contribution of the $\mathrm{CORH}$ to $\mathrm{RH}$ care provision in Kenya. We are only aware of two earlier studies that focused on CORH-our qualitative study and one other study on their involvement in provision of bilateral tubal ligation [16, 17]. The current study has also provided more insight in the role that associate clinicians play in healthcare provision in low-income countries. Rather than relying on existing records, a prospective study with measures of quality control could further assess the impact of task sharing in $\mathrm{RH}$ on health outcomes. Despite the costs of such a study, this should be considered as a better understanding of human resources for health has the potential to contribute significantly to better healthcare and better health.

\section{Endnotes}

${ }^{1}$ Associate clinicians and advanced-level associate clinicians include assistant medical officers, clinical officers, clinical associates, medical licentiates, surgical technicians, physician assistants, and advanced-practice nurses. See World Health Organization (2012). WHO recommendations: Optimizing health worker roles to improve access to key maternal and newborn health 
interventions through task shifting, Geneva, Switzerland, 2012. http://www.optimizemnh.org/Annexes/Annex_1_Cadre_definitions.pdf

${ }^{2}$ Information from KMTC - CORH students per batch since 2002 intake

${ }^{3}$ To manage post-partum haemorrhage

\section{Additional file}

Additional file 1: Clinical Officers Reproductive Health Questionnaire. (PDF $175 \mathrm{~kb}$ )

\section{Abbreviations}

CEmOC: Comprehensive emergency obstetric care; CORH: Clinical officer(s)reproductive health; CS: Caesarean section(s); MVA: Manual vacuum aspiration; RH: Reproductive health

\section{Acknowledgements}

The authors would like to thank Bridgit Adamou and the whole team from MEASURE Evaluation from Chapel Hill, United States of America, whose feedback was very helpful in improving the manuscript.

\section{Funding}

This publication was produced with the support of the United States Agency for International Development (USAID) under the terms of MEASURE Evaluation cooperative agreement AID-OAA-L-14-00004. Views expressed are not necessarily those of USAID or the United States government.

\section{Availability of data and materials}

The datasets used and/or analysed during the current study are available from the corresponding author on reasonable request.

\section{Authors' contributions}

$M D, R N$, and JN designed the study and participated in the data collection and analysis. MD drafted the first version of the manuscript. JA reviewed the study design. All authors reviewed and approved the final manuscript.

\section{Ethics approval and consent to participate}

The study obtained ethical approval in January 2016 from the Kenyatta National Hospital and University of Nairobi Ethics \& Research Committee (P645/10/2015). Consent was obtained from all participants and anonymity of participants and facilities was maintained throughout.

\section{Consent for publication}

Not applicable.

\section{Competing interests}

The authors declare that they have no competing interests.

\section{Publisher's Note}

Springer Nature remains neutral with regard to jurisdictional claims in published maps and institutional affiliations.

\section{Author details}

${ }^{1}$ Community Health Promotion Kenya, P.O. Box 1045, Mtwapa 80109, Kenya.

${ }^{2}$ Kenya Medical Training College, P.O. Box 30195, Nairobi 00100, Kenya.

Received: 5 November 2017 Accepted: 18 June 2018

Published online: 11 July 2018

\section{References}

1. World Health Organization. Fact Sheet No. 348. Geneva: World Health Organization; 2012a.

2. World Health Organization. Recommendations: Optimizing health worker roles to improve access to key maternal and newborn health interventions through task shifting. Geneva: World Health Organization; 2012b.
3. Mullan F, Freywot S. Non-physician clinicians in 47 sub-Saharan African Countries. Lancet. 2008;370:2158-63.

4. World Bank. (2015). Physicians (per 1,000 people). World Bank Data. [Online] 14 3. people. http://data.worldbank.org/indicator/SH.MED.PHYS.ZS.

5. World Health Organization. Global Health Observatory data repository. Aggregate data on health workers by category. [Online] 0702 2017. [Cited: 1209 2017.] http://apps.who.int/gho/data/node.main.A1444?lang= en\&showonly=HWF.

6. Pereira $C$, et al. Meeting the need for emergency obstetric care in Mozambique: Work performance and histories of medical doctors and assistant medical officers trained for surgery. BJOG. 2007;114:1530-3.

7. Chilopora G, Pereira C. Postoperative outcome of casesarean sections and other major emergency obstetric surgery by clinical officers and medical officers in Malawi. Hum Resour Health. 2007;5(1):17.

8. Vaz F, Bergström S, Vaz Mda L, Langa J, Bugalho A. Training medical assistants for surgery. Bull World Health Organ. 1999;77(8):688-91.

9. Kruk M, Pereira C, Vaz F, Bergström S, Galea S. Economic evaluation of surgically trained assistant medical officers in performing major obstetric surgery in Mozambique. BJOG. 2007;114(10):1253-60.

10. Pereira C, Bugalho A, Bergström S, Vaz F, Cotiro M. A comparative study of Caesarean deliveries by assistant medical officers and obstetricians in Mozambique. Br J Obstet Gynaecol. 1996;103(6):508-12.

11. Kenya National Bureau of Statistics \& ICF Macro. Kenya Demographic and Health Survey 2008-09. Claverton: KNBS \& ICF Macro; 2010.

12. Mbindyo $P$, Blaauq $D$, English $M$. The role of clinical officers in the Kenyan health system: A question of perspective. Hum Resour Health. 2013;11:32.

13. Karanja LM, Kakai R, Onyango RO. Participation of clinical officers in preventive health care services at rural health facilities in Kenya. African Journal of Health Sciences. 2012;21:107-12.

14. Kenya National Bureau of Standards, Ministry of Health, National Aids Control Council, Kenya Medical Research Institute, National Council for Population and Development, The DHS Program, \& ICF International. Kenya Demographic and Health Survey 2014. Nairobi: KNBS; 2015.

15. Kenya Ministry of Medical Services, \& Ministry of Public Health and Sanitation. Accelerating Attainment of Health Goals: The Kenya Health Sector Strategic and Investment Plan - KHSSP July 2012 - June 2018. Nairobi: Ministry of Medical Services and Ministry of Public Health \& Sanitation; 2013.

16. Community Health Promotion Kenya and Averting Maternal Death and Disability Program at Columbia University. Expanding Access to Caesarean Sections: A Rapid Assessment in Kenya. Mombasa: CHPK; 2014.

17. Kenya Ministry of Health, USAID, \& FHI360. Bilateral Tubal Ligation (BTL) Rapid Assessment: Provision of BTL and other Reproductive Health (RH) Services by Clinical Officers in Kenya. Kenya: MOH; 2013.

18. Ginsburg, O., Badwe, R., Boyle, P., Derricks, G., Dare, A., Evans, T., .. Sullivan, R. (2017). Changing global policy to deliver safe, equitable, and affordable care for women's cancers., The Lancet,389, 10071 871-880.

19. Kenyan Network of Organizations. Kenya Cancer Statistics \& National Strategies. [Online] [Cited: 1209 2017.] https://kenyacancernetwork. wordpress.com/kenya-cancer-facts/.

\section{Ready to submit your research? Choose BMC and benefit from:}

- fast, convenient online submission

- thorough peer review by experienced researchers in your field

- rapid publication on acceptance

- support for research data, including large and complex data types

- gold Open Access which fosters wider collaboration and increased citations

- maximum visibility for your research: over $100 \mathrm{M}$ website views per year

At BMC, research is always in progress.

Learn more biomedcentral.com/submissions 